\title{
Radiofrequency Catheter Ablation of WPW Syndrome in National Institute of Cardiovascular Diseases, Dhaka: Initial and Four Years Follow-up Results
}

\author{
MA Ali, MM Hossain, M Aziz, M Rahman, MS Hossain, MM Rashid, S Nabi, R Ahmed
}

Dept. of Cardiology, NICVD, Dhaka.

\begin{abstract}
:
Keywords:

Catheter

Background: Radiofrequency (RF) catheter ablation is an effective method of treatment of patients ablation, Radiofrequency ablation, WPW syndrome. with WPW syndrome. The purpose of this study was to analyze the initial and follow -up results of RF ablation of such cases in our hospital.

Methods: 255 cases with WPW syndrome that had delta wave in sinus rhythm ECG underwent electrophysiological studies in this hospital. All the cases underwent radiofrequency ablation. These cases are selected for analysis.

Results: Ablations were performed in these 255 patients between December 2005 and December 2008. One accessory pathway (AP) was found in 250 patients, two accessory pathways-in 05 patients. The mean duration of the procedure was $130 \pm 32 \mathrm{~min}$. The initial and overall success rate was $92.15 \%$ and $95.68 \%$ respectively. Major complications encountered are none.

Conclusions: RF ablation of WPW syndrome has good initial (92.15\%) and overall (95.68\%) success rate and low recurrence rate $(5.00 \%)$ at long term follow-up.
\end{abstract}

(Cardiovasc.j. 2010; 2(2) : 188-194)

\section{Introduction:}

Accessory pathway (AP) is a connection between the atria and ventricles that is capable of both antegrade and retrograde conductions in WPW syndrome. The electrocardiogram shows Delta wave during sinus rhythm and is associated with preexcitation. The patients are prone to paroxysmal orthodromic circus movement tachycardia. ${ }^{1-10}$ Sometimes the pathways can give rise to re-entrant tachycardias of the incessant character. ${ }^{1}$ Catheter ablation with the use of radiofrequency (RF) energy to treat these cases is being widely used as a primary therapeutic option. ${ }^{2,3} \mathrm{RF}$ energy can interrupt the pathway and breaks the circuit. This report analyses our four years initial and follow-up experiences of consecutive series of 255 patients who underwent $\mathrm{RF}$ catheter ablation of the manifest AP.

\section{Methods:}

\section{Population:}

From December 2005 until December 2008, 270 procedures (255 primary and 15 re-do) of $\mathrm{RF}$ catheter ablation were performed for 255 patients. The group of patients consisted of 175 males and 80 females aged $32 \pm 16$ years. All patients complained of symptomatic tachycardias (Table1). Some of the patients had accompanying diseases and are presented in (Table-III).
Electrophysiological study and radiofrequency ablation procedures:

The electrophysiological study and RF ablation was performed after informed written consent had been obtained and the administration of antiarrhythmic drugs had been discontinued for at least 3 plasma half-lives. The procedures were performed in a fasting state. Multipolar electrode catheters were positioned in the high right atrium, the His bundle region, the right ventricular apex and the coronary sinus (CS). The CS catheter was placed using the femoral approach.

The electrophysiological study included a standard protocol for intracardiac recording and pacing. Retrograde and anterograde AV nodal conduction, effective refractory periods of the AV node and the $\mathrm{AP}$, and the inducibility of AP-mediated arrhythmia were determined at a baseline. If tachycardia was not inducible, pacing protocols were repeated after the intravenous administration of Isoproterenol.

Heparin 3000-5000 IU was administered as an intravenous bolus before RF energy delivery. Leftsided AP ablation was performed by accessing left heart chambers via the femoral artery or the transseptal approach (using a standard transseptal puncture or through an open foramen Ovale).

Address of correspondence- Dr. M. Atahar Ali, Department of Cardiology, NICVD, Dhaka, Bangladesh. 


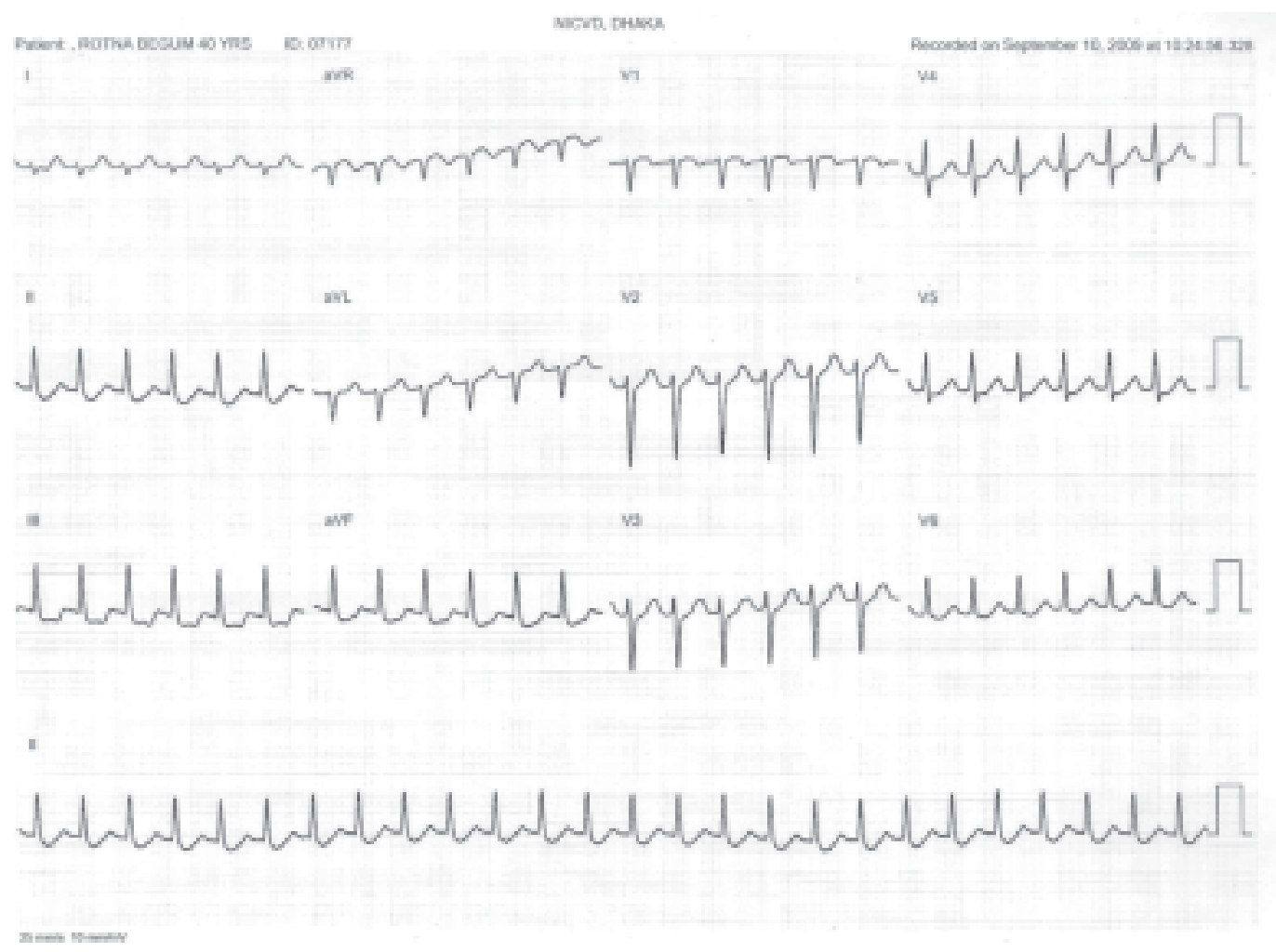

Fig-1- Regular narrow QRS tachycardia a rate of 188 bpm in patient with WPW syndrome.

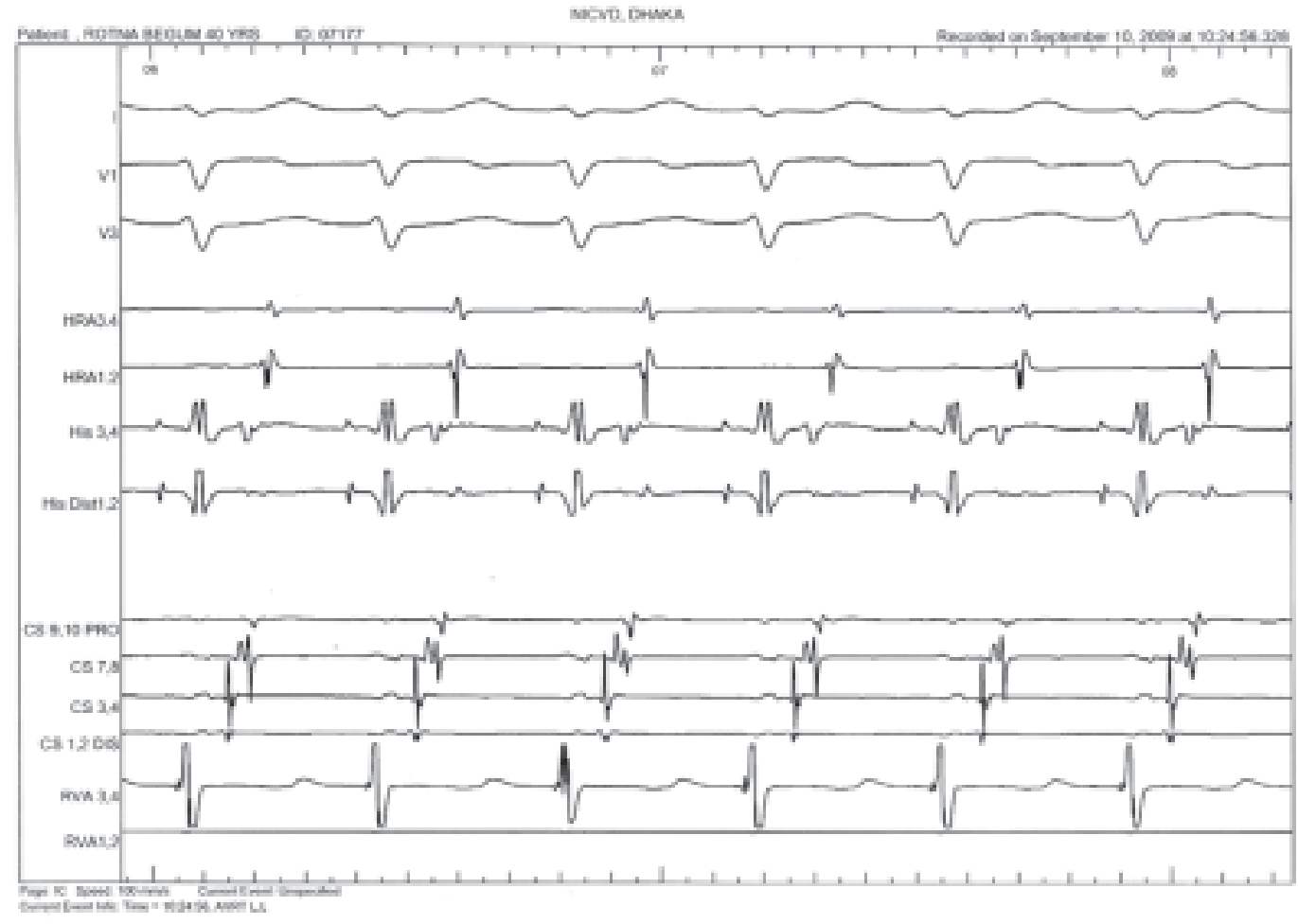

Fig-2: Surface and intracardiac electrograms are displayed showing tachycardia using accessory pathway. Closest VA with earliest A were registered at CS1. 


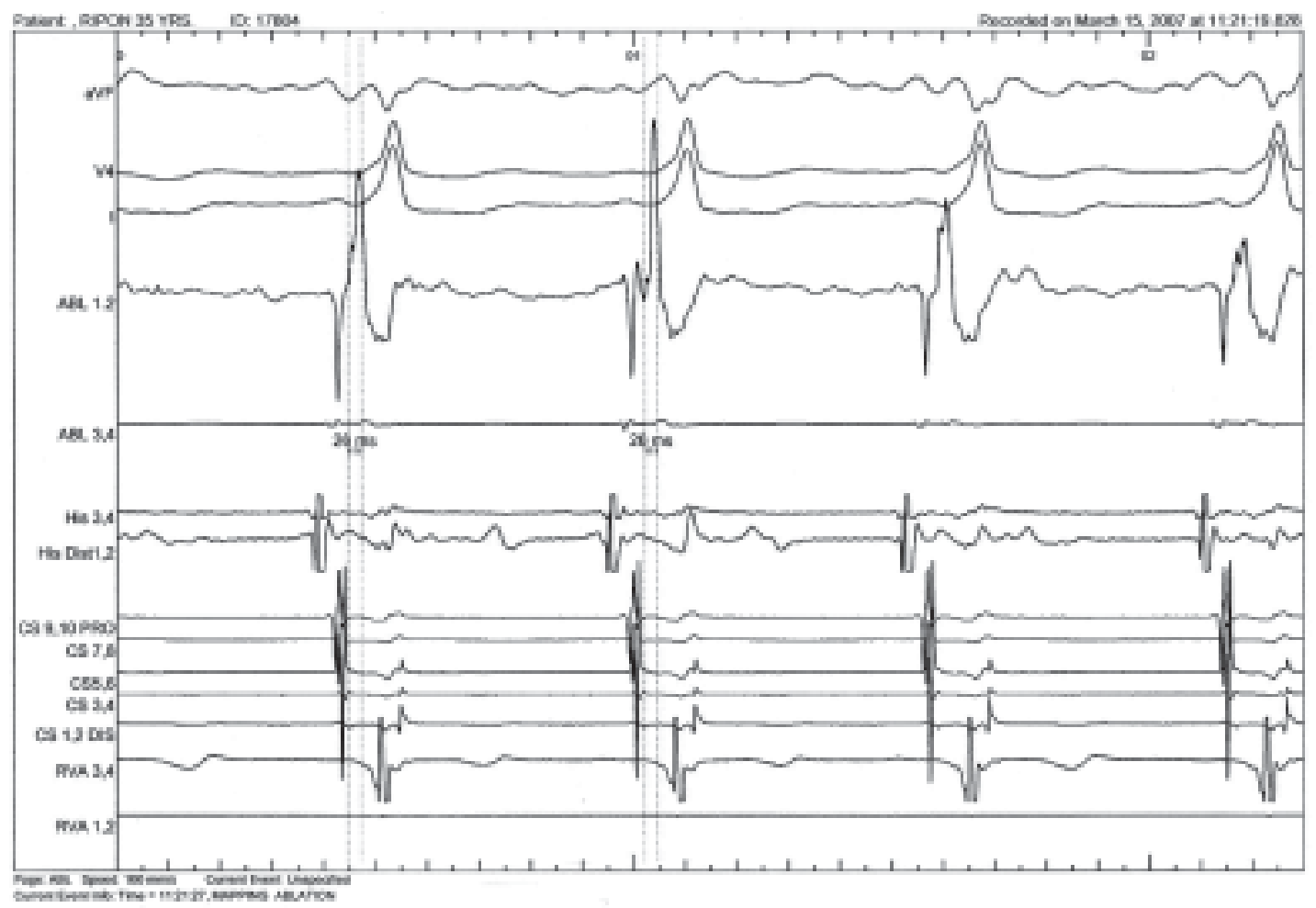

Fig-3: Surface and intracardiac electrograms showing mapping of manifest accessory pathway. Intracardiac ventricular electrogram in distal ABL catheter is 34 msec predelta in surface ECG.

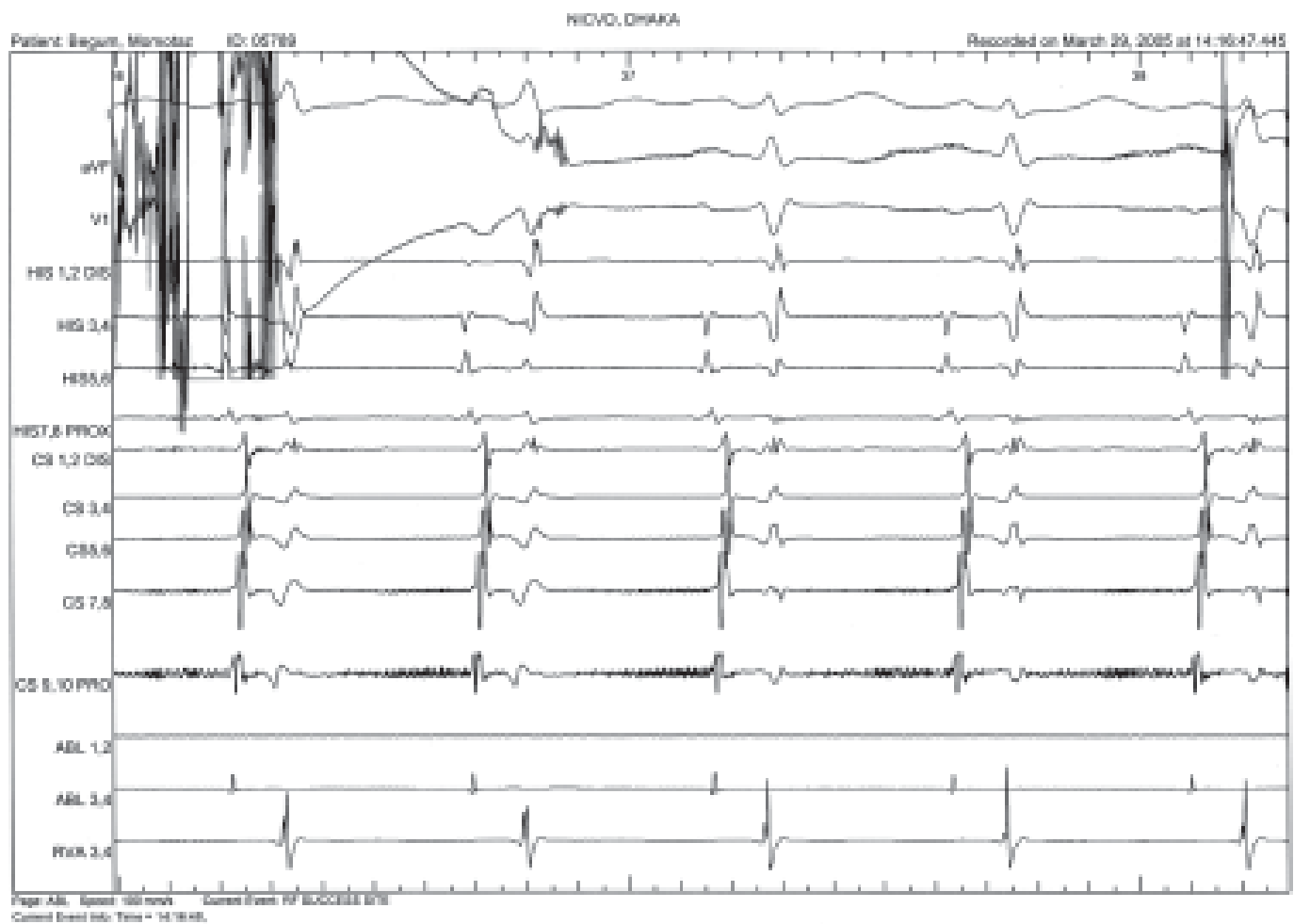

Fig-4: Surface and intracardiac electrograms showing RF ablation. In first 2 beats of surface ECG showing delta wave. With application of RF energy delta wave is disappeared indicating successful ablation. 
Outcome:

The results of the procedure will be either successful or unsuccessful. The success of RF ablation was defined by absence delta wave and AP mediated tachycardia. Primary success means successful procedure without major complications at initial attempt and overall success means total success that includes initial success plus re-do success.

\section{Follow-Up:}

Patients were monitored electrocardiographically for 24 hours after ablation. An electrocardiogram (ECG) was obtained after ablation and before discharge from hospital. Patients were followed clinically at out patient basis. Follow - up program was continued for 4 years. Each patient was followed-up at 6 month interval. All patients completed first visit, 92 $\%$ completed 2 visits, and $88 \%$ completed 3 visits. Ambulatory monitoring was performed in patients following ablation if they complained of palpitations, with repeat electrophysiologic testing as indicated.

\section{Statistical Methods:}

Data were presented as mean value \pm SD. Students $\mathrm{t}$ tests was applied to see difference between discrete variable. $\mathrm{P}$ value $<0.05$ were considered significant.

\section{Results:}

One AP was found in 250 patients, two APs-in 05 patients. The mean total procedure duration was $130 \pm 32 \mathrm{~min}$; the mean fluoroscopy time was $33 \pm 21 \mathrm{~min}$. The success of RF ablation was defined by the absence delta wave and APmediated tachycardia. RF ablation was determined as primary success in 235/255 (92.15\%) cases and overall success in 244/255 (95.68\%) cases (Table-IV). All the 20 primary ineffective procedures were repeated on elective date and 09 of 20 were successful. Thus the overall success rate became 244/255 (95.68\%). During 4 years follow-up 13 (5.00\%) patients showed recurrence of SVT.
Table-I

Clinical characteristics of 255 patients

\begin{tabular}{ll}
\hline Variables & Values \\
\hline Age (years) & $32 \pm 16($ range 13-66) \\
Men/women & $175(68.62 \%) /$ \\
& $80(31.38 \%)$ \\
Indications & \\
Symptomatic tachycardia & $255(100 \%)$ \\
Presyncope & $50(19.60 \%)$ \\
Recurrence after ablation & $13(5.00 \%)$ \\
\hline
\end{tabular}

Table-II

Antiarrhythmic drugs most frequently used before ablation

\begin{tabular}{lc}
\hline Drugs & No, \% \\
\hline Digitalis & $08(3.13 \%)$ \\
Metoprolol & $67(26.27 \%)$ \\
Sotalol & $23(9.01 \%)$ \\
Amiodarone & $12(04.70 \%)$ \\
Verapamil & $122(47.84 \%)$ \\
\hline
\end{tabular}

Table-III

Associated diseases in patients undergoing radiofrequency catheter ablation $(n=255)$

\begin{tabular}{lc}
\hline Associated diseases & Number of cases \\
\hline Aortic valve prosthesis & $1(0.39 \%)$ \\
Mitral valve stenosis & $04(1.56 \%)$ \\
Coronary artery disease & $11(4.31 \%)$ \\
Ebstein's anomaly & $12(4.70 \%)$ \\
Myocardial infarction & $08(3.13 \%)$ \\
AVNRT & $04(1.56 \%)$ \\
Tachycardiomyopathy & $04(1.6 \%)$ \\
\hline
\end{tabular}

The distribution of effectiveness of the procedures according to the localization of the AP is presented in Table-IV. The pathways were classified as anteroseptal, posteroseptal (left and right) posterior (left and right), right free wall and left lateral. The commonest pathway locations were left lateral 120/255 (47.05\%). The second highest pathway locations were posteroseptal 80/255 (31.37\%). Primary success was achieved at highest rate for left lateral locations (116/120, 96.66\%) followed by right posteroseptal $(70 / 67,95.71 \%$,). The least success rate was for anteroseptal pathways (2/5, $40 \%)$. 
Table-IV

Radiofrequency ablation efficacy distribution by pathway location $(n=255)$

\begin{tabular}{lcccc}
\hline Pathway location & No. of cases & $\begin{array}{c}\text { Primary success, } \\
\text { No(\%) }\end{array}$ & $\begin{array}{c}\text { Recurrences } \\
\text { No(\%) }\end{array}$ & $\begin{array}{c}\text { Overall success (primary } \\
\text { plus repeated), } \\
\text { No (\%) }\end{array}$ \\
\hline $\begin{array}{l}\text { Anteroseptal } \\
\text { Posteroseptal }\end{array} \quad$ Left & 5 & $2 / 5(40 \%)$ & 0 & 5 -Feb \\
$\quad$ Right & 10 & $8 / 10(80 \%)$ & 2 & 10 -Sep \\
Posterior & 70 & $67 / 70(95.71 \%)$ & 2 & $69 / 70$ \\
$\quad$ Left & 10 & $9 / 10(90 \%)$ & 1 & $10-\mathrm{Sep}$ \\
$\quad$ Right & 20 & $18 / 20(90.00 \%)$ & 2 & $20 / 20$ \\
Right Free Wall & 20 & $15 / 20(75.00 \%)$ & 3 & $17 / 20$ \\
Left Lateral & 120 & $116 / 120(96.66 \%)$ & 3 & $118 / 120$ \\
\hline Total & 255 & $235 / 255(92.15 \%)$ & $13(5.00 \%)$ & $244 / 255(95.68 \%)$ \\
\hline
\end{tabular}

Long-Term Follow-up Results:

Results at long-term follow-up were excellent in patients with successful procedures, with 219 patients (86\%) being asymptomatic during followup. However, 40 of the 255 successfully treated patients (16\%) were still taking antiarrhythmic drugs during long-term follow -up. Only $5 \cdot 0 \%$ of the successfully treated patients had recurrence of accessory pathway conduction during long-term follow-up. It is noteworthy that a significant proportion of patients $(41 \cdot 1 \%)$ with failed ablations were asymptomatic during follow-up, with less than half of them taking any antiarrhythmic medication. A possible explanation for this phenomenon would be a modification of the conduction properties of the pathway since an initially successful ablation (followed by recurrence) or a modification of the pathway conduction properties was achieved in approximately half of these patients. A late effect of the radiofrequency energy delivery after the end of the procedure would be another explanation, but this conjuncture remains speculative. Unfortunately, most patients refused to undergo a follow-up electrophysiological study so that followup electrophysiological data were available only in a small minority. Interestingly, the drugs most used in asymptomatic patients with failed procedures were class III drugs, whereas in patients with successful procedures these were mostly beta-blockers.

\section{Complications:}

Complications related to the procedure occurred in eight patients (3.13\%) (Table 5). In 4 patients developed hypotension, which was managed expectantly without further sequelae. In two patients convulsion was developed during procedure managed without the need for intervention. A large hematoma developed in one patient at an arterial puncture site and resolved within a few days without vascular compromise. Two patients were noted to have transient elevation of the ST segment; this resolved spontaneously and was felt to be related to effusive pericarditis. No complication was observed during 4 years follow up.

Table-V

Complications of Radiofrequency ablation.

\begin{tabular}{lc}
\hline Complications & Number (\%) \\
\hline Hypotension & $4(1.33 \%)$ \\
Convulsion & $2(0.66 \%)$ \\
Groin haematoma & $1(0.33 \%)$ \\
Pericarditis & $1(0.33 \%)$ \\
\hline
\end{tabular}

Discussion:

Our study is based on 255 cases of AP ablation in WPW syndrome a single centre. The overall success rate in our patients group was $95.68 \%$, this was comparable to that reported in a number of previous series. ${ }^{4-10}$ The primary success rate was $92.15 \% .20$ patients among the group from initial unsuccessful cases had to undergo redo procedures, 
09 of them got ultimate success and thereby the overall success rate became $95.68 \%$.

Closed-chest radiofrequency catheter ablation of arrhythmogenic substrate in a dog model was originally described by Huang and associates ${ }^{11}$ in 1987. The technique is conceptually simple. A catheter electrode is positioned at the ablation site, guided by flouroscopy and by the appearance of the electrogram recorded from the catheter tip. Radiofrequency energy is then applied through the catheter tip, creating a small lesion (less than 0.5 $\mathrm{cm}$ in diameter) at the catheter-tissue interface. ${ }^{12}$ The lesion results from thermal injury due to resistive heating. ${ }^{12}$ The accessory pathway in WolffParkinson-White syndrome is an ideal target because the position of the ablation catheter on the AV ring can be guided flouoroscopically and the accessory pathway can be identified by the appearance of the electrogram recorded from the catheter tip. The results of this study confirm the efficacy of radiofrequency catheter ablation as reported elsewhere. ${ }^{13}$ The technique requires angiographic skills to manoeuvre the catheters to the desired site and electrophysiologic skills to identify the appropriate target site by electrogram characteristics.

There are no clinical or electrophysiologic factors that contraindicate radiofrequency catheter ablation in a symptomatic patient. The only variable that has some relation to success appears to be location of the accessory pathway. In most series, as in our experience, right free wall and posteroseptal pathways are the most difficult to ablate. ${ }^{14,15}$ In general, ablation failure may be related to lack of precise localization of the pathway or poor catheter-tissue contact. These problems are particularly acute for posteroseptal pathways because of the complex anatomy in this region. In cases when a stable ablation catheter position cannot be achieved, the usage of long pre-shaped sheaths of the appropriate size gives a high success rate of AP ablation and probably is a cheaper alternative in comparison with the usage of several different disposable ablation electrodes.

The complication rate of $3.13 \%$ in our series is consistent with rates in other large series ${ }^{16-22}$. Although infrequent, some complications may be catastrophic. Many are related to operator error and inexperience. The amount of radiation our catheter operator was exposed to was small and well below the recommended occupational level with fluoroscopic times similar to ours. The excellent efficacy, low complication rate and convenience of radiofrequency catheter ablation allow it to be offered as initial therapy for symptomatic arrhythmias. It can be offered as a reasonable alternative to long-term pharmacologic therapy and is clearly easier and more cost-effective than surgery. Catheter ablation will probably become a one-day care procedure as further experience is gained.

In our experience, most difficulties occurred during anteroseptal and right free wall AP ablation. The complication rate is low and includes some minor complications.

\section{Conclusions:}

Radiofrequency ablation of pathways in WPW syndrome has good overall success rate (94\%) with long-term low recurrence rate. Major complications requiring surgical intervention may be required, but this series experienced none.

\section{References:}

1. Aidietis A, Marinskis G, Jurkuvenas P, et al successful radiofrequency catheter ablation of permanent form of atrioventricular juntional reciprocating tachycardia using CARTO system: case report. Kardiologijos Seminarai 2002; 8:41-44.

2. Swartz JF, Tracy CM, Fletcher RD, Radiofrequency endocardial catheter ablation of accessory pathways atrial insertion sites. Circulation 1993; 87:487-499.

3. Kuck K-H, Schlueter M, Geiger M, Siebels J, Duckeck W. Radiofrequency current catheter ablation of accessory atrioventricular pathways. Lancet 1991; 337: 1557-1561.

4. Calkins H, Young P, Miller JM, et al. Catheter ablation of accessory pathways. atrioventricular nodal reentrant tachycardia, and the atrioventricular junction final results of a prospective multicenter clinical trial. Circulation 1999; 99: 262-270.

5. Xie B, Heald SC, Camm AJ, Rowland E, Ward DE, Radiofrequency catheter ablation of accessory atrioventricular pathways primary failure and recurrence of conduction. Heart 1997; 77:363-368.

6. Borggrefe M, Budde T, Podczeck A, Breithardt G. High frequency alternating current ablation of an accessory pathway in humans. J Am Coll Cardiol 1987; 10: 57682.

7. Jackman WM, Wang X, Friday KJ et al. Catheter ablation of accessory atrioventricular pathways (WolffParkisnson-White syndrome) by Radiofrequency current. N Engl J Med 1991; 324: 1605-11. 
8. Lesh MD, van Hare GF, Schamp DJ et al. Curative percutancous catheter ablation using radiofrequency energy for accessory pathways in all locations: Results in 100 consecutive patients. J Am Coll Cardiol 1992; 19: 1303-9.

9. Chen X, Kottkamp H, Hindricks G et al. Recurrence and late block of accessory pathway conduction following radiofrequency catheter ablation. $J$ Cardiovasc Electrophysiol 1994; 5: 650-8.

10. Atahar M. Hossain MM, Ali M, Haque SA, Alam MS, Rahman S, Chowdhury AW, Islam KQ et al. Radiofrequency Catheter Ablation of Atrioventricular Nodal Reentrant Tachycardia. Bangladesh Heart Journal 2005; 20(2): 39-43).

11. Campbell RWF, Smith RA, Gallagher JJ et al: Atrial fibrillation in the preexcitation syndrome. Am J Cardiol 1977: 40: 514-520.

12. Lesh MD, Van Hare GF, Schamp DJ et al: Curative percutaneous catheter ablation using radiofrequency energy for accessory pathways in all locations: results in 100 consecutive patients. J Am Coll Cardiol 1992; 19: 1303-1309.

13. Langberg J, Lee M, Chin M et al: Radiofrequency catheter ablation: the effect of electrode size on lesion volume in vitro. Pacing Clin Electrophysiol 1990; 13:1242- 1248 .

14. Bardy GH, Ivey TD, Coltorti F et al: Developments, complications and limitations of catheter-mediated electrical ablation of posterior accessory atrioventricular pathways. Am J Cardiol 1988; 61: 309-316.
15. Morady F, Scheinman MM, Kou WH et al: Long-term results of catheter ablation of a posteroseptal accessory atrioventricular connection in 48 patients. Circulation 1989; 79: 1160-1170.

16. Huang SK, Bharati S, Graham AR et al: Closed chest catheter dessication of the atrioventricular junction using radiofrequency energy: a new method of catheter ablation. J Am Coll Cardiol 1987; 9: 349-358.

17. Budde T, Breithardt G, Borggrefe M et al: Erste Erfahrungen mitder Hochfrequenzstromablation des AV-leitungssystems beim Menschen. Z Kardiol 1987; 76: 204-211.

18. Langberg JJ, Chin MC, Rosenqvist M et al: Catheter ablation of the atrioventricular junction with radiofrequency energy. Circulation 1989; 80: 1527-1535.

19. Franklin JO, Langberg JJ, Oeff M et al: Catheter ablation of canine myocardium with radiofrequency energy. Pacing Clin Electrophysiol 1989; 12: 170-176.

20. Calkins H, Sousa J, El-Atassi R et al: Diagnosis and cure of the Wolff-Parkinson- White syndrome or paroxysmal supraventricular tachycardia during a single electrophysiologic test. $N$ Engl J Med 1991; 324: 1612-1618.

21. Jackman WM, Wang X, Friday KJ et al: Catheter ablation of accessory atrioventricular pathways (WolffParkinson-White syndrome) by radiofrequency current. N Engl J Med 1991; 324: 1605-1611.

22. Lesh MD, Van Hare GF, Schamp DJ et al: Curative percutaneous catheter ablation using radiofrequency energy for accessory pathways in all locations: results in 100 consecutive patients. J Am Coll Cardiol 1992; 19: $1303-1309$. 